\title{
Rarity types among plant species with high conservation priority in Switzerland
}

\author{
Olivier Broennimann', Pascal Vittoz ${ }^{1}$, Daniel Moser ${ }^{2}$ and Antoine Guisan' \\ 1 Université de Lausanne, Laboratoire de Biologie de la Conservation (LBC), \\ Département d'Ecologie et d'Evolution (DEE), Bâtiment de Biologie, \\ CH-1015 Lausanne; e-mail: olivier.broennimann@unil.ch \\ 2 Centre du Réseau Suisse de Floristique (CRSF), Altenbergrain 21, CH-3013 Berne
}

Manuscript accepted 15 March 2005

\begin{abstract}
Broennimann O., Vittoz P., Moser D. and Guisan A. 2005. Rarity types among plant species with high conservation priority in Switzerland. Bot. Helv. 115: 95-108.

We investigated the ecogeographic characteristics of 118 Swiss plant species listed as those deserving highest conservation priority in a national conservation guide and classified them into the seven Rabinowitz' rarity types, taking geographic distribution, habitat rarity and local population size into account. Our analysis revealed that species with high conservation priority in Switzerland mostly have a very restricted geographic distribution in Switzerland and generally occur in rare habitats, but do not necessarily constitute small populations and are generally not endemics on a global scale. Moreover, species that are geographically very restricted on a regional scale are not generally restricted on a global scale. By analysing relationships between rarity and IUCN extinction risks for Switzerland, we demonstrated that species with the highest risk of extinction are those with the most restricted geographic distribution; whereas species with lower risk of extinction (but still high conservation priority) include many regional endemics. Habitat rarity and local population size appeared to be of minor importance for the assessment of extinction risk in Switzerland, but the total number of fulfilled rarity criteria still correlated positively with the severity of extinction risk. Our classification is the first preliminary assessment of the relative importance of each rarity type among endangered plant species of the Swiss flora and our results underline the need to distinguish between a regional and a global responsibility for the conservation of rare and endangered species.
\end{abstract}

Key words: Rabinowitz' rarity types, conservation practice, extinction risk, geographic distribution, rarity assessment, vascular plants.

\section{Introducton}

In the effort to conserve biodiversity worldwide, resources are often directed toward protecting rare species since these are assumed to undergo the highest risk of 
extinction (Gaston 1994). But is this assumption true? To answer this question, it is first necessary to define "rare" species, which is a non-trivial issue. Each researcher or practitioner probably has his own intuitive definition of what makes a species rare in the landscape (Gaston 1994), and there is no universal definition and measure of rarity. Depending on how it is defined, rarity may relate differently to extinction risk, so that an explicit and appropriate definition is essential if conservation priorities are based on rarity. The explicit definition of rarity is also important in studies that try to explain why species are rare, e.g. by comparing traits of rare and common species (Bevill and Louda 1999; Murray et al. 2002; Lavergne et al. 2004; Pohlman et al. 2005) or by searching for factors that limit the abundance of individual species (Schemske et al. 1994; Yates and Broadhurst 2002; Burne et al. 2003; Evans et al. 2004; Yates and Ladd 2004). The fact that no single cause of rarity has been identified by these studies may be due to the many forms that rarity can take in nature.

The simplest way to assess the degree of rarity of a species is to quantify its geographic distribution. Two measures applied by the IUCN (2001) are the extent of occurrence (EOO; area in square kilometers of the minimum convex polygon including all known populations of a species) and the area of occupancy (AOO; sum of kilometer plots containing populations). These measures are easily applicable and require little information about the species, but they do not take into account the different forms of rarity that exist in nature. For example, the IUCN criteria cannot be used to compare the rarity of two endemic Alpine species, Artemisia nivalis (a species forming very small populations and restricted to Drabion hoppeanae communities at $3000 \mathrm{~m}$ a.s.l.) and Carex baldensis (which forms large colonies in several vegetation types). Both species have approximately the same EOO and AOO but their demographic and ecological characteristics are completely different, so that $A$. nivalis is actually much rarer than $C$. baldensis.

A more comprehensive measure of rarity has been proposed by Rabinowitz (1981; Rabinowitz et al.1986), who defined seven rarity types based on a (i) geographic range, (ii) habitat specificity and (iii) local population size (Tab. 1). Species are rare if they have a restricted range, if they occur only in one or few specific habitats, and/or if their populations are always small. Species fulfilling two or three of the criteria are particularly rare, those fulfilling none of the criteria are common (Tab. 1). Rabinowitz' classification has been applied to numerous taxa and locations in the world (Kattan 1992; Arita 1993; Saetersdal and Birks 1997; Pitman et al. 1999; Yu and Dobson 2000).

Rabinowitz' rarity types also lead to a more differentiated view on the relationship between rarity and extinction risk (Gaston 1994) in that the type of rarity may determine how endangered a species is. If so, measures to conserve biodiversity should not focus on rare species in general but more specifically on those with certain rarity features. Furthermore, as the rarity criteria can be assessed at regional scale (e.g. one country) or global scale (worldwide), they may lead to different priorities for the conservation of regional and global biodiversity.

In this study we characterise the rarity of 118 plant species from the Swiss flora, which have been selected as those deserving highest conservation priority in Switzerland. We address the following specific questions: (1) What types of rarity characterise these species with high conservation priority? (2) How does rarity relate to extinction risk across this set of species? (3) Do species that are geographically restricted at a regional scale also have a restricted distribution at global scale? We finally discuss some implications for the regional versus global conservational responsibility for rare and endangered species. 
Tab. 1. Rabinowitz' typology of rarity. Categories represent different rarity types based on the combinations of three dichotomic ecogeographic criteria as defined by Rabinowitz et al. (1986). When possible, an example of the flora present in Switzerland is given for each rarity type.

\begin{tabular}{|c|c|c|c|c|c|}
\hline \multirow{2}{*}{\multicolumn{2}{|c|}{$\begin{array}{l}\text { Geographic distribution } \\
\text { Habitat rarity }\end{array}$}} & \multicolumn{2}{|c|}{ Wide } & \multicolumn{2}{|c|}{ Narrow (restricted) } \\
\hline & & Unspecific & Specific & Unspecific & Specific \\
\hline \multirow{2}{*}{$\begin{array}{l}\text { Local } \\
\text { population } \\
\text { size }\end{array}$} & $\begin{array}{l}\text { Somewhere } \\
\text { large }\end{array}$ & $\begin{array}{l}\text { Common } \\
\text { Trifolium } \\
\text { pratense }\end{array}$ & $\begin{array}{l}\text { Type A } \\
\text { Spiranthes } \\
\text { aestivalis }\end{array}$ & $\begin{array}{l}\text { Type D } \\
\text { Tulipa sylvestris } \\
\text { subsp. australis }\end{array}$ & $\begin{array}{l}\text { Type E } \\
\text { Myosotis } \\
\text { rehsteineri }\end{array}$ \\
\hline & $\begin{array}{l}\text { Everywhere } \\
\text { small }\end{array}$ & $\begin{array}{l}\text { Type B } \\
?\end{array}$ & $\begin{array}{l}\text { Type C } \\
\text { Dianthus } \\
\text { gratianopolitanus }\end{array}$ & $\begin{array}{l}\text { Type F } \\
\text { Senecio } \\
\text { halleri }\end{array}$ & $\begin{array}{l}\text { Type G } \\
\text { Artemisia } \\
\text { nivalis }\end{array}$ \\
\hline
\end{tabular}

\section{Materials and Methods}

\section{Species data}

The plant species analysed in this paper are those described in the Swiss guide for conservation of flowering plants and ferns (Käsermann and Moser 1999). This guide compiles information about 132 plant species in Switzerland resulting from detailed surveys during the past ten years. It provides a baseline to conserve the existing sites and to propose further actions that need to be taken for the conservation. The data on which this guide was elaborated (all species observations with their locations and population sizes) were provided by the Swiss Floristic Network in Geneva (www.villege.ch/cjb/rsf). Among the 132 species, presently extinct ones were included in the analysis if possible, based on their ecological and demographical features just before they become extinct. However, 14 extinct or critically endangered species had to be excluded because no information about local population size was available, leaving 118 species for the analysis.

\section{Rarity criteria and rarity types}

The geographic distribution of each species in Switzerland was quantified from the dot maps of the Swiss guide for conservation (Käsermann and Moser 1999). Only indications of presences or probable presences since 1998 were taken into account. Probable presences correspond to recent convincing information that have not been checked in the field for diverse reasons (lack of time, inappropriate weather or phenology during the sampling) or to historical populations not confirmed recently but probably still existing since occurring in undisturbed habitats (Käsermann and Moser 1999). On a grid of 226 plots of $16 \times 16 \mathrm{~km}^{2}$ covering the whole Swiss territory, the number of plots occupied by each species was counted and expressed as percentage of all plots (hereafter called \% coverage). A narrow geographic distribution was defined as a coverage of less than $1 \%$ ( $\leq 2$ plots) or less than $10 \%$ ( $\leq 23$ plots).

To see whether species geographically restricted on a regional scale also tend to be restricted on a global scale, worldwide geographic distribution was assessed using the information about "general distribution and threats" in the guide for conservation. A distribution was considered to be narrow at worldwide scale if the species is endemic to a small region of Europe (for example: Orobic, Insubrian or Pennian Alps). 
The habitat of each species is indicated in the guide for conservation following a published habitat typology (Delarze et al. 1998). We classified the rarity of these habitats on the basis of the Swiss ordinance concerning the protection of nature and landscape (OPN 451.1), which edicts the list of habitats deserving protection in Switzerland. Habitats listed in this ordinance have been scientifically recognized as rare or irreplaceable for threatened and rare animals and plants (OPN 451.1). Species occurring only in rare habitats according to this list were considered as having a restricted habitat. For species occurring evenly in two habitats, the more abundant habitat was decisive, whereas for species occurring in several habitats but predominantly in one of them, the main habitat was evaluated. The habitat rarity criterion applied in this paper does not correspond to habitat specificity as defined by Rabinowitz et al. (1986) as it measures the rarity of the habitat instead of considering the specificity of a species to a few habitats. This is, to our point of view, a better estimation of the availability of suitable sites for a species in the landscape.

Population size was indicated on a six-point ordinal scale (less than 10 individuals, 11 to 20,21 to 50,51 to 100,101 to 200 and more than 200) for most species observations in the database of the Swiss Floristic Network. In clonal plants, "individuals" were units that could easily be counted, i.e. either single ramets or entire tussocks, depending on the growth form. A species was considered to have local populations "everywhere small" when all known population consisted of less than 200 individuals.

Rarity types were attributed following the dichotomic procedure described by Rabinowitz et al. (1986; Tab. 1), using both thresholds for a restricted geographic distribution in Switzerland (1\% and 10\% coverage, respectively). A list of the evaluated species with their local population size, habitat rarity, geographic distribution and rarity type is given in Appendix 1.

\section{Relationship between rarity type and extinction risk}

The risk of extinction for every species was obtained from the guide for conservation (Käsermann and Moser 1999). It corresponds to the risk of extinction in Switzerland as defined by the IUCN/SSC (1994). This classification does not correspond exactly to that of the last Swiss Red List (Moser et al. 2002), but it was used here because it was based on the same data as our attribution of rarity types. The 1994 classification differs from the 2001 classification in that includes a category LR (lower risk), which was subsequently split into NT (near threatened) and LC (least concern). For each IUCN category, we determined the proportion of species fulfilling each of the three rarity criteria - restricted geographic distribution, rare habitat or small population size. Chi-square tests were then performed to test if the proportion of species fulfilling a specific rarity criterion differed among IUCN categories. The tests were computed by considering the overall proportion of species fulfilling the rarity criteria as expected values.

\section{Results}

The main ecogeographic characteristic of the plant species with high conservation priority in Switzerland is a restricted geographic distribution in this country: $94 \%$ of the 118 species cover less than $10 \%$ of the $16 \times 16 \mathrm{~km}$ plots, and $39 \%$ of them even cover less than $1 \%$ (Fig 1). In contrast, the proportion of regional endemics is fairly low $(24.6 \%)$ and unrelated to coverage in Switzerland (Fig. 1a). The two other rarity crite- 


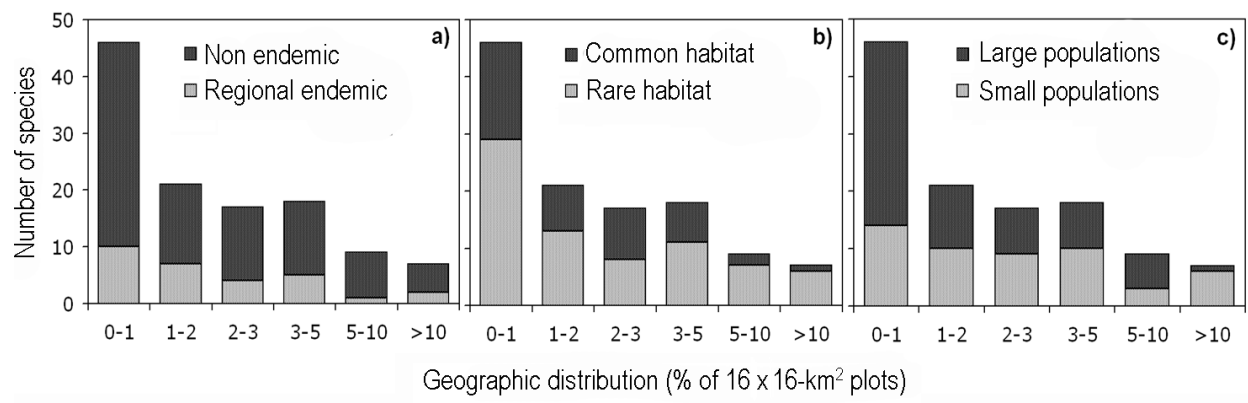

Fig. 1. Ecogeographic characteristics of 118 endangered plant species in relation to their geographic distribution in Switzerland: (a) proportion of regional endemics, (b) proportion of species occurring in rare habitats, and (c) proportion of species with everywhere small populations.

ria are mostly fulfilled by species with a relatively broad distribution in Switzerland: $81.3 \%$ of the species with more than $5 \%$ coverage have rare habitats, but only $59.8 \%$ of the species with less than $5 \%$ coverage (Fig. 1b). Likewise, $85.7 \%$ of the species with more than $10 \%$ coverage have everywhere small populations, but only $41.4 \%$ of the species with less than $10 \%$ coverage (Fig. 1c).

The rarity types attributed to each species are given in Appendix 1. Table 2 summarizes the number of species per rarity type for each of the two geographic distribution thresholds ( $1 \%$ and $10 \%$ coverage, respectively). With the $1 \%$ threshold, rarity types are represented in the sequence $\mathrm{A}>\mathrm{G}>\mathrm{C}>\mathrm{D}>\mathrm{B}=\mathrm{E}>\mathrm{F}$, with 17 species considered as common. With the $10 \%$ threshold, types A, B, C and common are less frequent. The rank order is then $\mathrm{E}>\mathrm{G}>\mathrm{D}>\mathrm{F}>\mathrm{A}>\mathrm{C}>\mathrm{B}$, with only one species classified as common (Dracocephalum ruyschiana).

Rarity types differ significantly among IUCN categories of extinction risk (Tab. 3 ). The percentage of regional endemic species is greatest $(74 \%)$ for species with low risk of extinction (LR) and decreases with increasing extinction risk; $0 \%$ of the extinct species are regional endemics (Tab. 3). The pattern is opposite for geographic distribution in Switzerland: only $21 \%$ of the species with low risk of extinction have a restricted geographic distribution in Switzerland ( $<1 \%$ coverage), whereas $68 \%$ of the species with high risk of extinction and all extinct species do so (Tab. 3). The other relationships between IUCN categories and rarity features are not statistically supported. However, the percentages of species with rare habitat and of species with small populations also tend to increase with the risk of extinction (Tab. 3). The IUCN risk of extinction correlates positively with the number of fulfilled rarity criteria for both geographic distribution thresholds (Fig. 2).

\section{Discussion}

Ecogeographic characteristics of highly endangered plants in Switzerland

We have underlined the prevalent demographical and ecological features that characterize species with high conservation priority in Switzerland. Most of them are narrowly distributed on a local scale (Fig. 1). Interestingly, almost all widely distributed 
Tab. 2. Rarity types in the endangered Swiss flora (118 species with high conservation priority): number of species classified in each rarity type using a geographic distribution threshold of $1 \%$ and in parentheses, $10 \%$ (percentage of $16 \times 16 \mathrm{~km}^{2}$ plots covered). See Methods section for a definition of the rarity criteria.

\begin{tabular}{llclcc}
\hline Geographic distribution & \multicolumn{2}{c}{ Wide } & \multicolumn{2}{c}{ Narrow (restricted) } \\
\hline Habitat rarity & Common & Rare & Common & Rare \\
\hline $\begin{array}{l}\text { Local } \\
\text { population } \\
\text { size }\end{array}$ & $\begin{array}{l}\text { Somewhere } \\
\text { large }\end{array}$ & $\mathbf{1 7}(1)$ & $\mathbf{3 0}(5)$ & $\mathbf{1 1}(29)$ & $\mathbf{1 0}(35)$ \\
\cline { 2 - 5 } & $\begin{array}{l}\text { Everywhere } \\
\text { small }\end{array}$ & $\mathbf{1 0}(0)$ & $\mathbf{1 5}(1)$ & $\mathbf{6}(14)$ & $\mathbf{1 9}(33)$ \\
\hline
\end{tabular}

Tab. 3. Relationship between rarity and extinction risk. The percentage of species fulfilling various rarity criteria is given for the entire data set (total) as well as for each IUCN category. $\chi^{2}$ values and p-values indicate whether the percentages differ significantly among IUCN categories.

\begin{tabular}{lrrrrrrrr}
\hline IUCN category & Total & LR & VU & EN & CR & EX & $\chi^{2}$ & p \\
\hline Number of species & 118 & 19 & 31 & 39 & 22 & 7 & & \\
\hline \% of regional endemics & 24 & 74 & 29 & 10 & 9 & 0 & 26.00 & 0.000 \\
\% in <1\% of $16 \times 16 \mathrm{~km}^{2}$ plots & 38 & 21 & 19 & 36 & 68 & 100 & 16.22 & 0.003 \\
\% in <10\% of $16 \times 16 \mathrm{~km}^{2}$ plots & 94 & 84 & 87 & 100 & 100 & 100 & 0.61 & 0.962 \\
\% with rare habitat & 62 & 26 & 65 & 77 & 55 & 100 & 7.07 & 0.132 \\
\% with small populations & 44 & 37 & 29 & 46 & 55 & 86 & 5.16 & 0.272 \\
\hline
\end{tabular}

species - Liparis loeselii, Spiranthes aestivalis, Cypripedium calceolus, Eryngium alpinum, Aquilegia alpina, Dracocephalum ruyschiana - are well known forbs with attractive flowers, which may have biased botanists toward considering these species to be highly endangered (i.e. risk of picking). We also demonstrated that species with high conservation priority generally occur in rare habitats, but do not necessarily constitute small populations (Fig. 1).

Rarity types, IUCN categories and conservation priority in Switzerland

The percentage of species in a flora attributed to each rarity type obviously depends on the criteria and thresholds used to define the classes (Tab. 1). Nevertheless, we strongly believe that this classification provides a useful preliminary assessment of the relative importance of each rarity type among threatened plant species in the Swiss flora. Some patterns might even hold more generally: the rank order of rarity types found here with the $1 \%$ threshold for geographic distribution resembles the sequence found in Britain ( $\mathrm{A}>\mathrm{E}>\mathrm{C}=\mathrm{D}>\mathrm{G}>\mathrm{B}>\mathrm{F}$; Rabinowitz et al. 1986). In both studies, type $\mathrm{A}$ is most frequent and type $\mathrm{F}$ least frequent. 


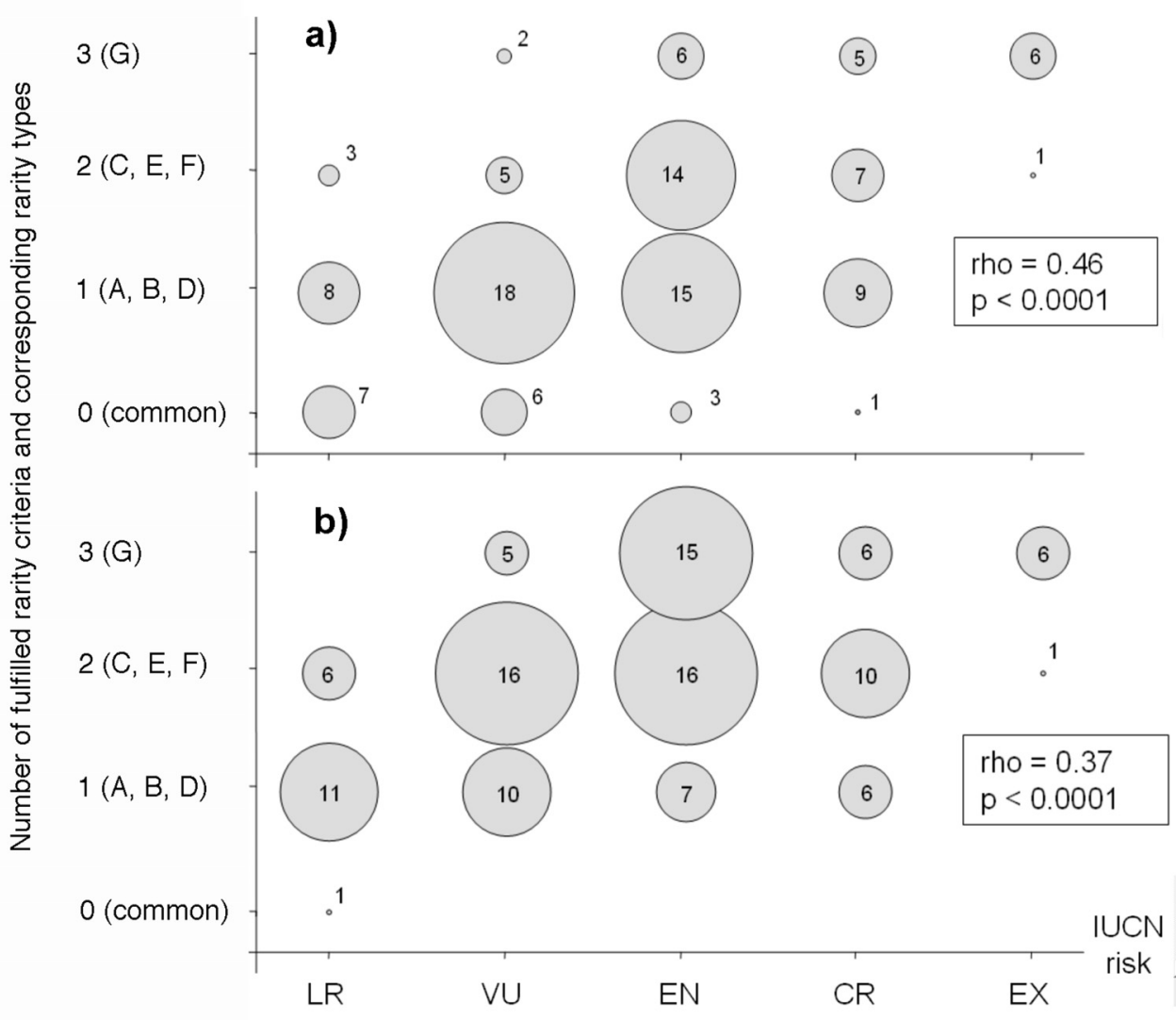

Fig. 2. Relationship between the number of fulfilled rarity criteria (categories as in Tab. 1) and IUCN extinction risks. Bubble size and numbers in the plots represent the number of species in each category, using a threshold of (a) $1 \%$ and (b) $10 \%$ for geographic distribution in Switzerland. IUCN categories of extinction risk are LR = low risk, $\mathrm{VU}=$ vulnerable, $\mathrm{EN}=$ endangered, $\mathrm{CR}=$ critically endangered, EX = extinct. Spearman rank correlations and their significance are given.

We also demonstrated that species with the highest risk of extinction are those with the most restricted geographic distributions in Switzerland. In contrast, rare habitats and small populations, when considered alone, did not seem to constitute pertinent factors to assess extinction risk, which is surprising at first sight. This pattern reveals that geographic distribution is presently the most important criterion to decide if a species is endangered or not. It reflects the overriding importance given to the criteria extent of occurrence (EOO) and area of occupancy (AOO) in the definition of the IUCN categories (IUCN 1994, 2001). However, the significant positive correlation found here between the number of fulfilled rarity criteria and IUCN risks shows that habitat rarity and small population size also contribute to making a species prone to extinction. 
This result provides further support to the use of rarity classifications in conservation practice. Since species with a high degree of rarity usually undergo a severe risk of extinction, they deserve high local concern and conservation priority. Thus, Rabinowitz' rarity criteria could complement Red Lists as tools to identify species deserving priority in conservation action.

\section{Global versus regional implications}

The ecogeographic characteristics of the plant species analyzed in the study are specific to Switzerland. A different classification would have been obtained for some species if rarity criteria had been based on worldwide eco-floristic data. Such classifications would require global databases, which are unfortunately not yet available. However, we clearly demonstrated that very few highly endangered species in Switzerland are both regionally restricted and endemic on a worldwide scale. This might be due to the small area of the country and to the fact that Swiss frontiers do not coincide with ecogeographic boundaries. For example, many Mediterranean species have their northern distribution limit within Switzerland because they cannot migrate to the other side of the Alps.

This contrast supports the view of Murray and Lepschi (2004) that theories trying to account for local rarity are incomplete for the majority of species because they fail to account for different degrees of rarity in different places. This problem was already noted by Rabinowitz et al. (1986), who argued that differences in rarity status depending on the geographic area considered are not a drawback of their classification, but rather emphasize that rarity must be considered at a variety of spatial scales.

Nevertheless, differences between local and worldwide rarity raise the more fundamental question of local versus global responsibility for species conservation. This question is underlined in our study by the relationship between extinction risk in Switzerland and worldwide endemicity (Tab. 3): species with the highest risk of local extinction were not endemics on a global scale. As these particular species are not endemics, they are likely to receive high conservation priority only when they become highly endangered at a local scale. The worst risk of not attributing a high conservation priority to a species that would be largely distributed over the world, but becoming rare at each national scale (e.g. due to increasing habitat destruction and fragmentation) would be to observe simultaneous extinctions in all countries. Although an unlikely situation, it remains a possible option that deserves to be considered seriously in national and international conservation strategies.

\section{Conclusions}

Our study shows that species given high conservation priority in Switzerland can be subdivided into three subsets: (1) species characterised by a restricted coverage of the Swiss territory and generally having a high risk of extinction in Switzerland; (2) endemic species that do not face a particularly high risk of extinction in Switzerland but have still been given conservation priority because of their endemicity on a global scale; and (3) species with a broad geographic distribution but either rare habitats or small populations or attractive flowers (high risk of picking). We believe that taking all these criteria into account - e.g. by calculating Rabinowitz' rarity types - would allow a better assessment of the endangerment of species before their extinction risk increases to the point that it is denoted by a restricted geographic distribution. 


\section{Résumé}

Les caractéristiques éco-géographiques des plantes menacées listées dans le guide pour la conservation du CRSF ont été analysées et une classification de ces espèces selon leur type de rareté a été effectuée en tenant compte de leur répartition géographique, de la rareté de leur habitat et de la taille de leur population. L'analyse met en évidence que ces espèces prioritaires pour la conservation ont une aire de répartition très restreinte en Suisse, sont souvent typiques de milieux rares, mais ne constitue pas forcément de grandes populations et ne sont généralement pas endémiques à échelle mondiale. De plus, les espèces à répartition restreinte en suisse n'ont pas plus tendance à être restreintes au niveau mondial. La relation entre rareté et risque d'extinction UICN en Suisse à été étudiée. Nous démontrons ici que les espèces avec le plus fort risque d'extinction sont celles ayant une aire de répartition particulièrement restreinte, alors que les espèces présentant un faible risque sont majoritairement constituées d'endémiques au niveau mondial. La rareté du milieu et la taille de population semblent par contre être de moindre importance pour déterminer les risques d'extinction en Suisse. Cette classification est la première estimation de l'importance des types de rareté parmi les plantes fortement menacées de la flore suisse. Quelques implications concernant la responsabilité régionale et mondiale en lien avec la conservation des plantes rares et menacées sont discutées.

\section{References}

Arita H.T. 1993. Rarity in Neotropical Bats - Correlations with Phylogeny, Diet, and Body-Mass. Ecol. Appl. 3: 506-517.

Bevill R.L. and Louda S.M. 1999. Comparisons of related rare and common species in the study of plant rarity. Conserv. Biol. 13: 493-498.

Burne H.M., Yates C.J. and Ladd P.G. 2003. Comparative population structure and reproductive biology of the critically endangered shrub Grevillea althoferorum and two closely related more common congeners. Biol. Conserv. 114: 53-65.

Delarze R., Gonseth Y. et Galland P. 1998. Guide des Milieux naturels de Suisse - Ecologie Menaces - Espèces caractéristiques. Delachaux and Niesté S.A, Lausanne.

Evans M.E.K., Menges E.S. and Gordon D.R. 2004. Mating systems and limits to seed production in two Dicerandra mints endemic to Florida scrub. Biodivers. Conserv. 13: 1819-1832.

Gaston K.J. 1994. Rarity. Chapman \& Hall, London.

IUCN 1994. IUCN Red List Categories. Prepared by the IUCN Species Survival Commission. The World Conservation Union, Gland.

IUCN 2001. IUCN Red List Categories. Prepared by the IUCN Species Survival Commission. The World Conservation Union, Gland.

Käsermann C. et Moser D.M. 1999. Fiches pratiques pour la conservation: Plantes à fleurs et fougères, Etat: octobre 1999. OFEFP, Berne.

Kattan G.H. 1992. Rarity and vulnerability - the Birds of the Cordillera Central of Colombia. Conserv. Biol. 6: 64-70.

Lavergne S., Thompson J.D., Garnier E. and Debussche M. 2004. The biology and ecology of narrow endemic and widespread plants: a comparative study of trait variation in 20 congeneric pairs. Oikos 107: 505-518.

Moser D.M., Gygax A., Bäumler B., Wyler N. and Palese R. 2002. Red List of threatened ferns and flowering plants in Switzerland. Edition 2002. OFEFP, Berne.

Murray B.R. and Lepschi B.J. 2004. Are locally rare species abundant elsewhere in their geographical range? Austral Ecol. 29: 287-293.

Murray B.R., Thrall P.H., Gill A.M. and Nicotra A.B. 2002. How plant life-history and ecological 
traits relate to species rarity and commonness at varying spatial scales. Austral Ecol. 27: 291-310.

Pitman N.C.A., Terborgh J., Silman M.R. and Nuez P. 1999. Tree species distributions in an upper Amazonian forest. Ecology 80: 2651-2661.

Pohlman C.L., Nicotra A.B. and Murray B.R. 2005. Geographic range size, seedling ecophysiology and phenotypic plasticity in Australian Acacia species. J. Biogeogr. 32: 341-351.

Rabinowitz D. 1981. Seven forms of rarity. In: Synge H. (ed.), The biological aspects of rare plants conservation. Wiley, New York, 205-217.

Rabinowitz D., Cairns S. and Dillon T. 1986. Seven forms of rarity and their frequency in the flora of British Isles. In: Soule M. (ed.), Conservation Biology: The science of scarcity and diversity. Sinauer Associates, Sunderland, 1882-1204.

Saetersdal M. and Birks H.J.B. 1997. A comparative ecological study of Norwegian mountain plants in relation to possible future climatic change. J. Biogeogr. 24: 127-152.

Schemske D.W., Husband B.C., Ruckelshaus M.H., Goodwillie C., Parker I.M. and Bishop J.G. 1994. Evaluating approaches to the conservation of rare and endangered plants. Ecology 75 : 584-606.

Yates C.J. and Broadhurst L.M. 2002. Assessing limitations on population growth in two critically endangered Acacia taxa. Biol. Conserv. 108: 13-26.

Yates C.J. and Ladd P.G. 2004. Breeding system, pollination and demography in the rare granite endemic shrub Verticordia staminosa ssp. staminosa in south-west Western Australia. Austral Ecol. 29: 189-200.

Yu J.P. and Dobson F.S. 2000. Seven forms of rarity in mammals. J. Biogeogr. 27: 131-139. 


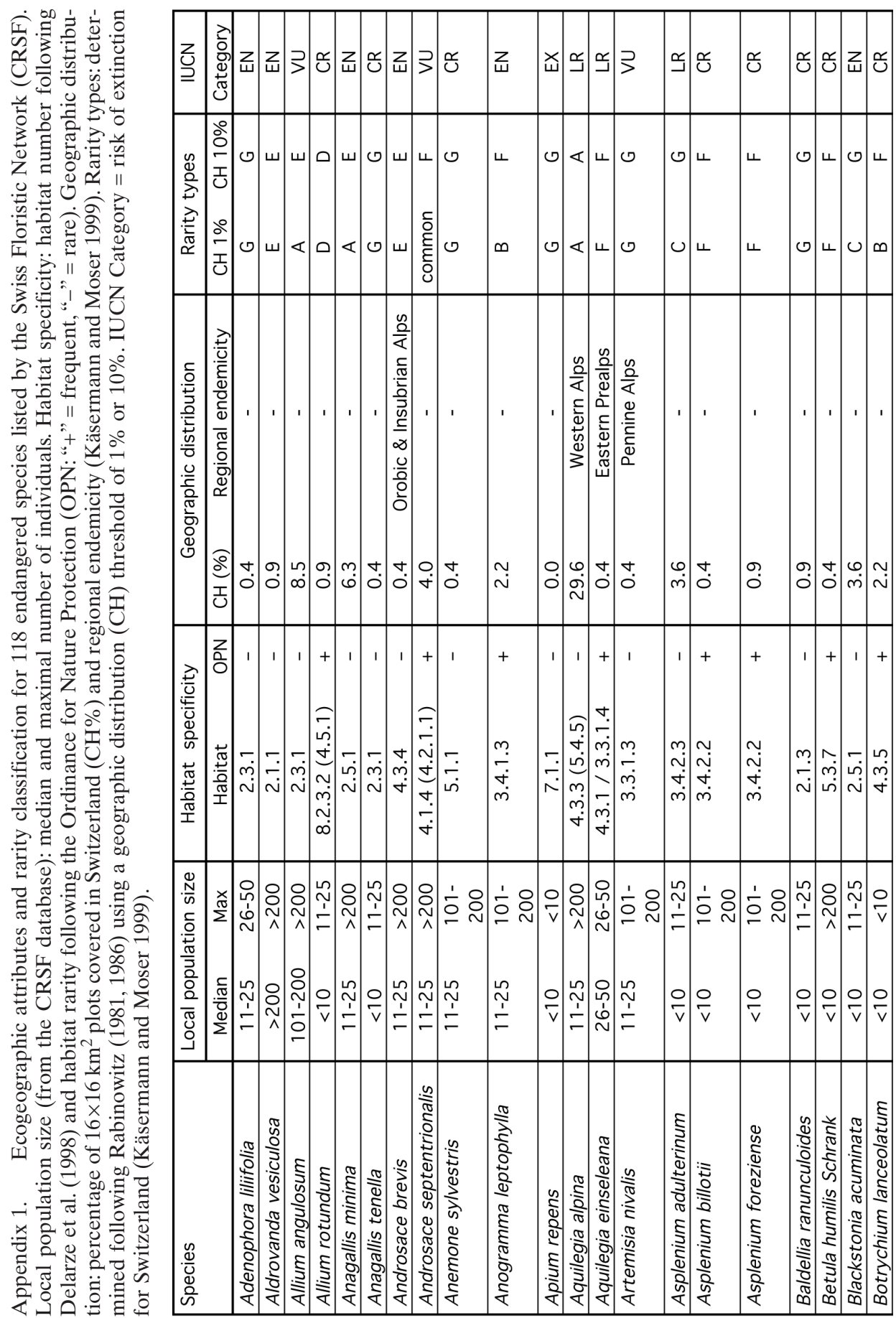




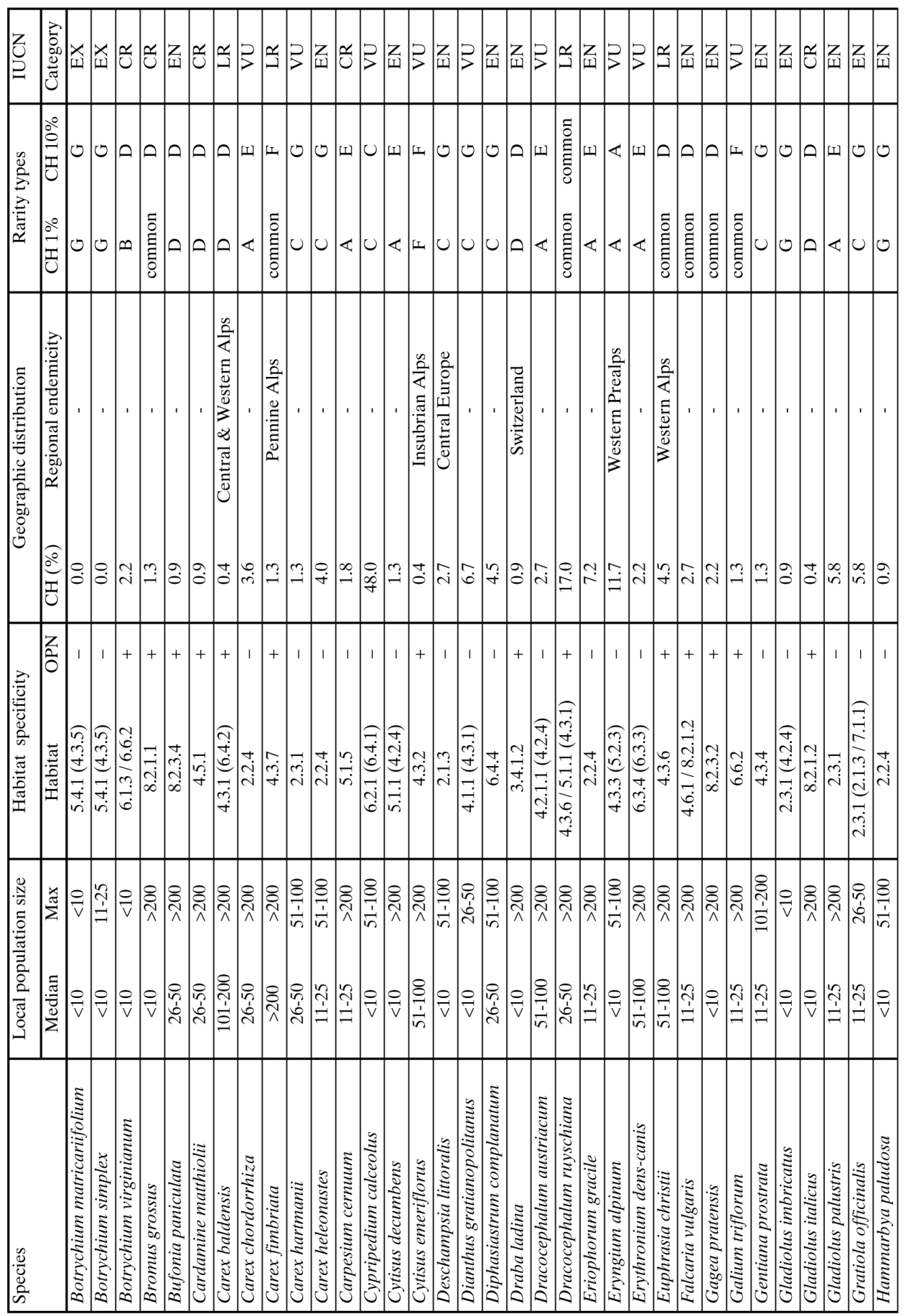




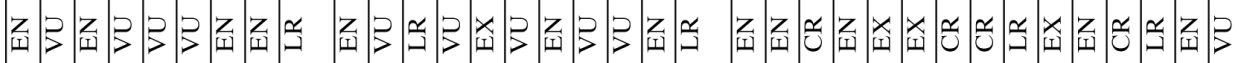

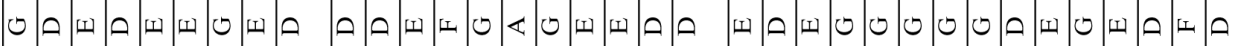

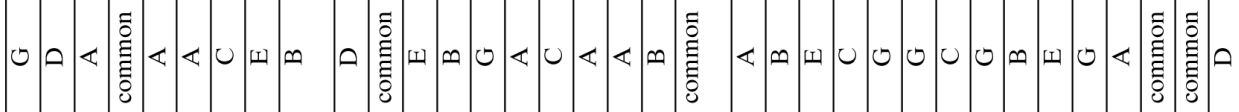

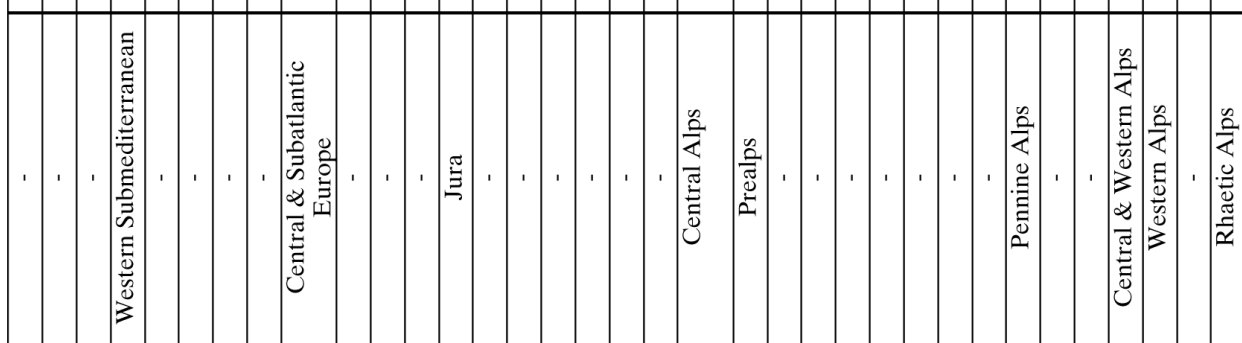

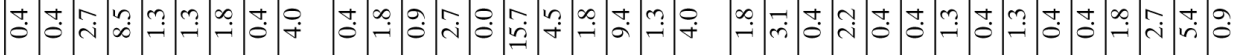

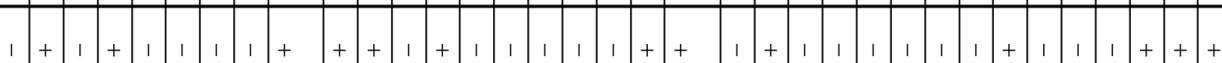
药

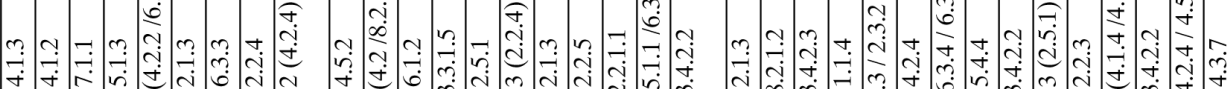

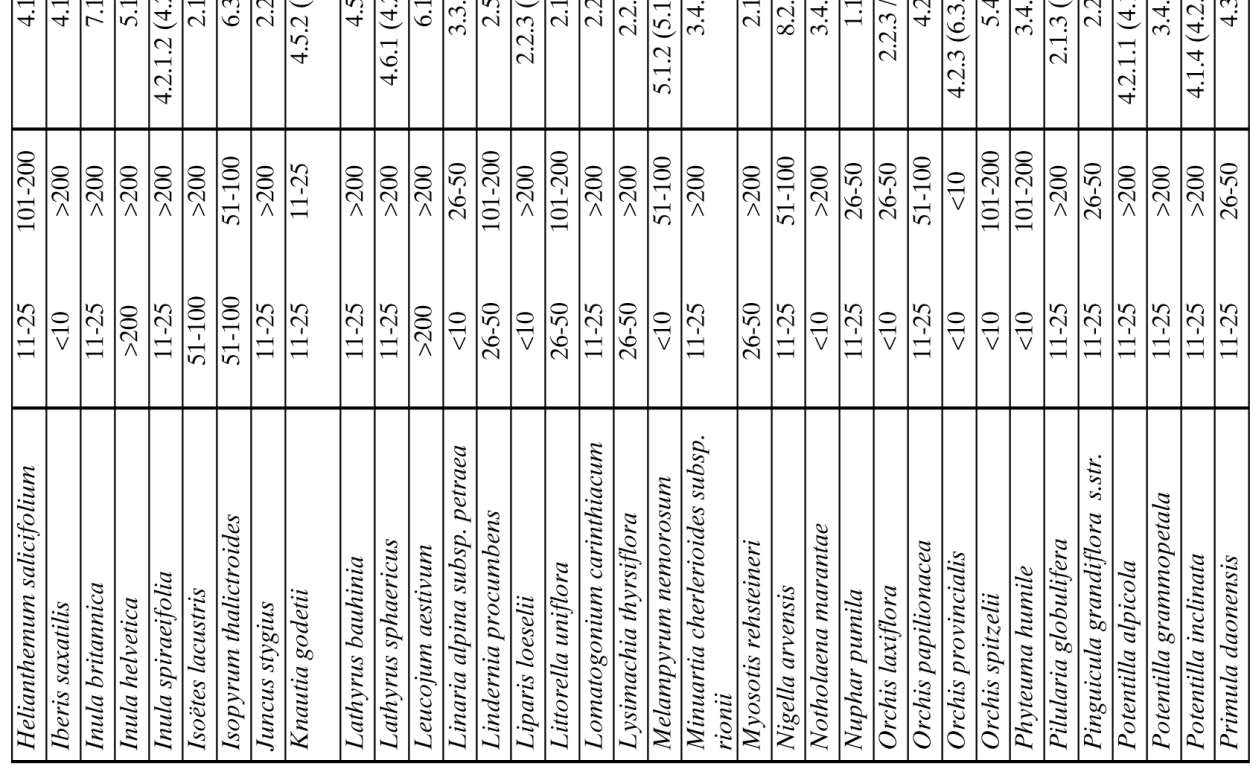




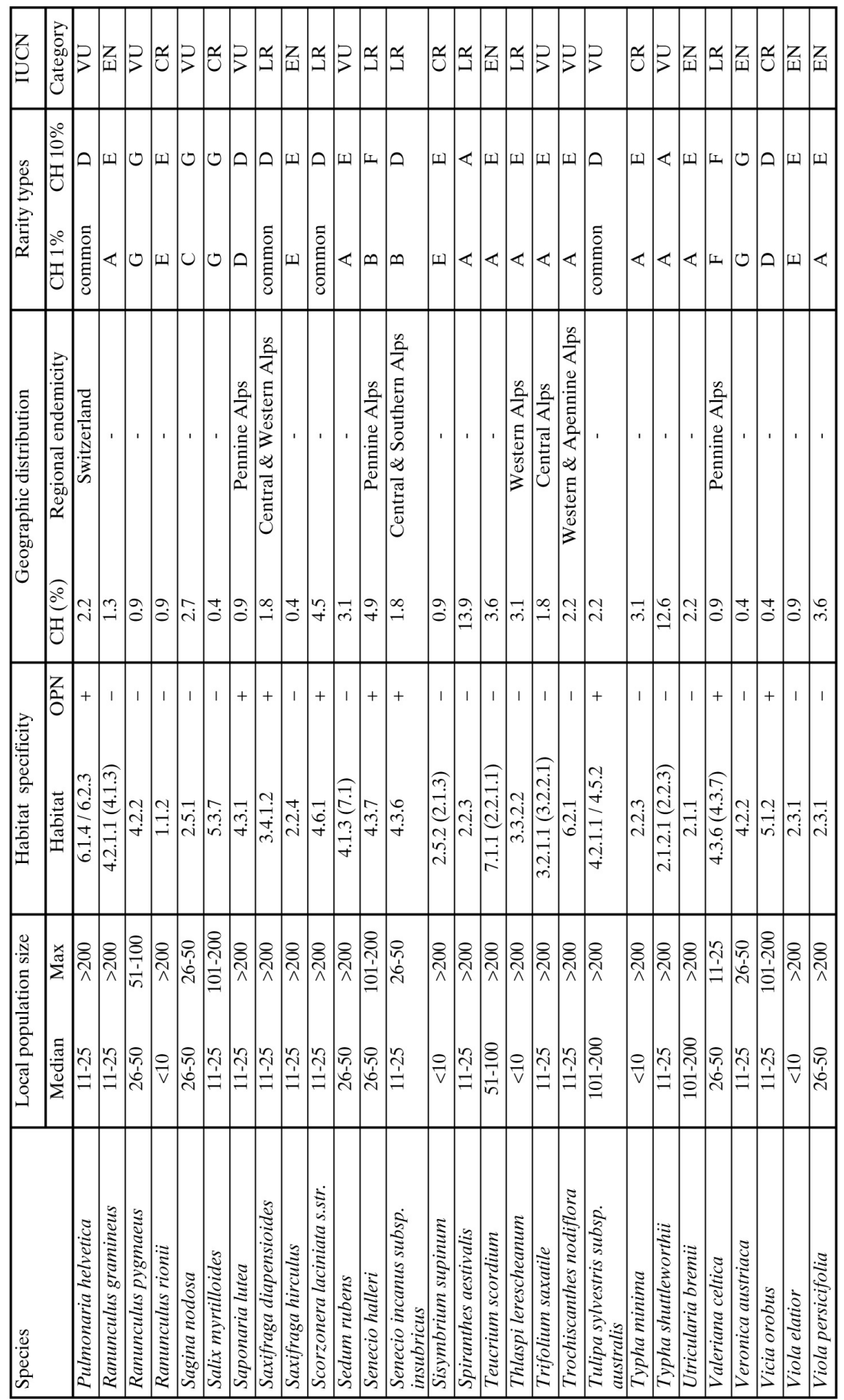

